\title{
Analisis Predictive Maintenance Mesin Overhead Crane PT. Bromo Steel Indonesia
}

\author{
Sofian Hadi $^{1)}$, Dayal Gustopo Setiadjit ${ }^{2}$, Dimas Indra Laksmana ${ }^{3)}$ \\ ${ }^{1}$ Mahasiswa Pasca Sarjana Jurusan Teknik Industri ITN Malang \\ ${ }^{2}$ Dosen Pasca Sarjana Jurusan Teknik Industri ITN Malang \\ ${ }^{3}$ Dosen Pasca Sarjana Jurusan Teknik Industri ITN Malang \\ Email :Sofianhadie67@gmail.com
}

\begin{abstract}
Abstrak
Permasalahan yang sering terjadi pada proses produksi di PT. Bromo Steel Indonesia yaitu kerusakan pada mesin overhead crane.Kerusakan yang terjadi pada mesin tersebut, mengakibatkan dampak buruk bagi perusahaan, dimana terhentinya proses produksi. Tujuan dalam penelitian ini adalah memperbaiki Standart Operating Prosedure.Berdasarkan hasil penelitian dalam memperbaikiStandard Operating Procedure (SOP) dalam hal perawatan dan pemeliharaan mesin dengan metode Risk Based Maintenance yang berdasarkan pemilihan komponen kritis dari frekuensi kerusakan, mahalnya harga komponen, skala probabilitas dan identikasi resiko, kemudian dianalisis dalam risk register, untuk dilakukan mitigasi resiko dari hasil rating risk. Hasil penelitian ini memperbaiki sistem perawatan di PT Bromo Steel Indonesia dengan melihat skala prioritas kerusakan mesin sehingga pihak perusahaan dapat menentukan kebijakan dalam meminimalisir kerugian dari resiko yang akan terjadi.
\end{abstract}

Kata Kunci : Predictive Maintenance, Standart Operating Procedure, Risk Based Maintenance, Risk Register.

\section{Pendahuluan}

Seiring dengan kemajuan ilmu pengethuan dan teknologi (IPTEK) dalam bidang industri, perusahaan akan berusaha terus berkembang untuk mencapai target, sasaran atau tujuan yang telah ditentukan. Salah satu faktor penunjang keberhasilan dalam pencapaian tujuan perusahaan adalah pemeliharaan mesin dan peralatan.PT. Bromo Steel Indonesia adalah perusahaan manufaktur (General Contraktor) yang bergerak dalam bidang pembuatan pressure vessel (bejana tekan), steel structure (struktur baja), agro industri dan lain-lainnya. Permintaan pasar yang meningkat dari tahun ke tahun, baik dari wilayah regional, maupun nasional, mendorong pihak perusahaan untuk meningkatkan produktifitas dalam melakukan proses produksi terutama dalam hal perawatan mesin. Perawatan adalah kegiatan untuk memelihara atau menjaga fasilitas dan peralatan pabrik dan penggantian yang diperlukan agar terdapat suatu keadaan operasi yang memuaskan sesuai dengan yang direncanakan [1].Perawatan mesin yang dilakukan perusahaan tersebut, masih bersifat corrective maintenance dan breakdown maintenance yaitu perawatan dilakukan ketika mesin mengalami kerusakan dan hanya melakukan penggantian komponen yang mengalami kerusakan serta belum ada tindakan untuk mengetahui indikasi gejala akan kerusakan pada mesin tersebut. 
Tabel 1. Data Downtime Mesin Overhead Crane

\begin{tabular}{|c|c|c|c|c|c|c|}
\hline No & $\begin{array}{c}\text { Komponen } \\
\text { Overhead } \\
\text { Crane }\end{array}$ & Frekuensi & $\begin{array}{c}\text { Downtime } \\
(\mathbf{J a m})\end{array}$ & $\begin{array}{c}\text { Persentase } \\
(\mathbf{\%})\end{array}$ & $\begin{array}{c}\text { Rata-rata } \\
\text { Perbaikan } \\
(\mathbf{J a m})\end{array}$ & $\begin{array}{c}\text { Corrective } \\
\text { Maintenance Cost/ } \\
\text { Failure }\end{array}$ \\
\hline $\mathbf{1}$ & Control Panel & 48 & 63,67 & 26,13 & 1,326 & Rp10.167.585 \\
\hline $\mathbf{2}$ & Hoist Crane & 51 & 116,08 & 24,98 & 2,276 & Rp54.111.006 \\
\hline $\mathbf{3}$ & Wheel \& railway & 18 & 48,82 & 20,04 & 2,712 & $\mathrm{Rp} 25.001 .205$ \\
\hline $\mathbf{4}$ & Insulated Bridge & 15 & 16,78 & 6,89 & 1,119 & Rp19.914.778 \\
\hline \multicolumn{2}{|r|}{ Jumlah } & 132 & 245,35 & 100 & & Rp109.194.575 \\
\hline
\end{tabular}

Atas dasar permasalahan pada tabel 1.maka diperlukan sebuah pendekatan pemeliharaan yang lebih baik dan yang dapat menurunkan rasio downtime padamesin overhead crane double girder pada sistem produksi perusahaan tersebut agar jadwal produksi tidak terganggu. Dalam penelitian ini bertujuan merancang Standart Operating Procedure berdasarkan penjadwalan predictive maintenancedengan metode Risk Based Thinking. Penelitian ini yang bertujuan sebagai berikutyaitu memperbaikiStandart Operating Prosedure Sistem perawatan mesin dan peralatan di PT. Bromo Steel Indonesia.

\section{Metodologi Penelitian}

\section{Pemilihan Komponen Kritis Berdasarkan MetodeRisk Based Maintenance}

Dalam pemilihan komponen kritis perlu adanya improvement yang berdasarkan risk based maintenance yang di implementasikan ke dalam risk register. Risk register berfungsi untuk memitigasi resiko yang ada dalam setiap aktifitas proses dan melakukan pemecahan masalah dari resiko tersebut. Seperti pada gambar 1 dibawah ini:

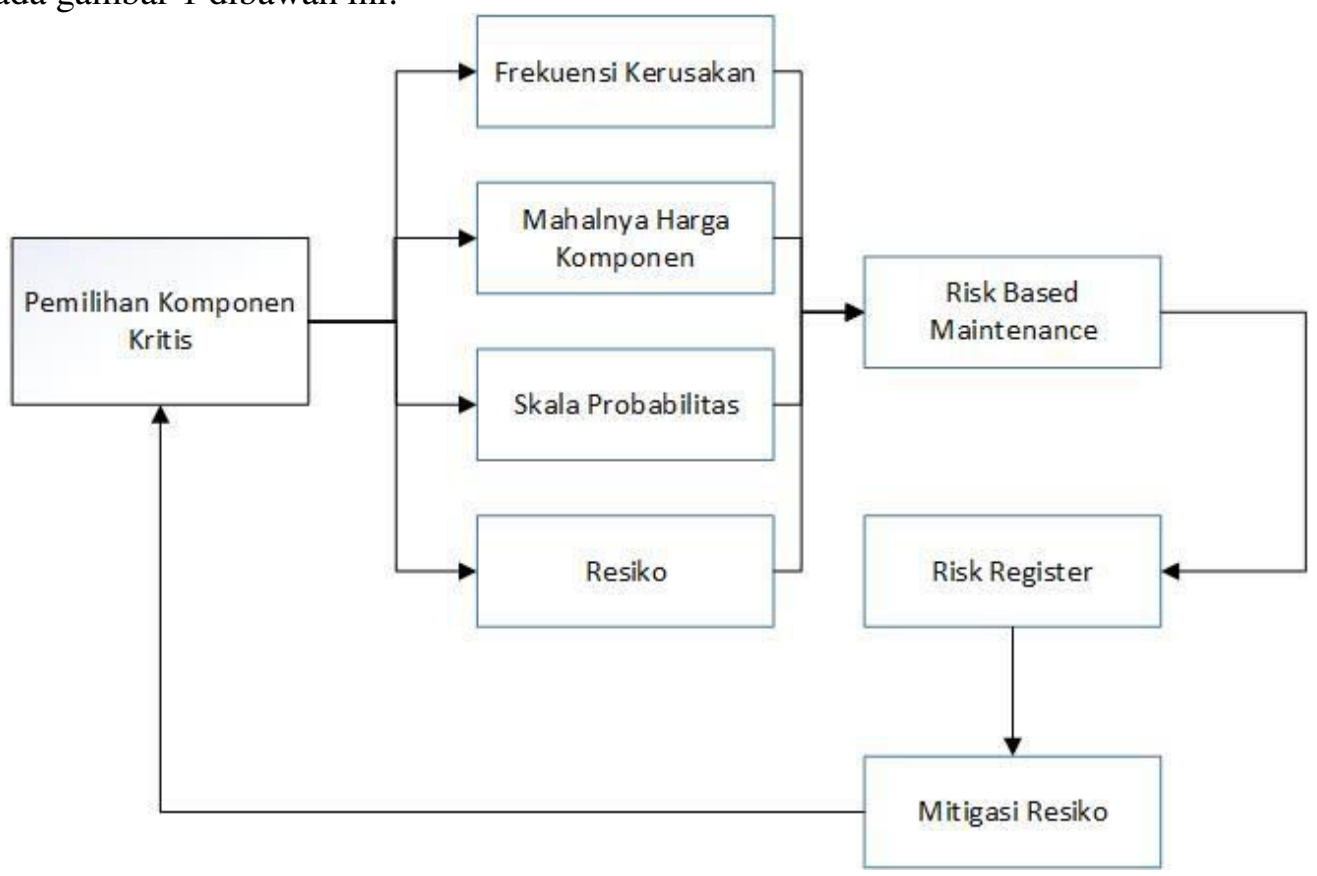

Gambar1. Model Konseptual SOP 


\section{Hasil Penelitian}

\section{Pemilihan Komponen Kritis Berdasarkan Metode Risk Based Maintenance}

Dari kerusakan mesin overhead crane terkait frekuensi dan mahalnya komponen akan dilakukan suatu identifikasi pada area produksi PT. Bromo Steel Indonesia terkait masalah yang akan diperbaiki. Berikut adalah hasil identifikasi gap yang ada yaitu:

1. Manajemen harus melakukan pemeliharaan secara menyeluruh dan konsisten mesin overhead crane sebagai aset perusahaan.

2. Perusahaan harus memonitoring hasil perbaikan atau perawatan mesin yang telah dilakukan.

3. Membuat catatan atau data historis terkait informasi kerusakan mesin atau peralatan sepeti form laporan pemeliharaan agar identifikasi masalah dapat diketahui.

4. Membuat jadwal perawatan pencegahan dan perbaikan mesin.

5. Mengevaluasi kinerja teknisi setelah melakukan perawatan dan perbaikan mesin.

\section{Risk Assessment.}

Tahapan dalam menentukan risk assessment adalah identifikasi resiko, menganalisis dan evaluasi dari resiko itu sendiri [2]. Identikasi resiko bertujuan menentukan aktifitas keruskan mesin yang membahayakan.Penentuan aktifitas kerusakan mesin yang beresiko kemudian dilakukan pencatatan dan pemberian kode agar memudahkan pengolahan data.Hasil pengkodean resiko kemudian dianalisis agar dapat dilakukan penilaian dari dampak dan probabilitas akibat resiko kerusakan mesin. Tingkatan likelihood untuk mengukur probabilitas terjadinya resiko dapat dilihat pada tabel2 yaitu:

Tabel 2. Skala Probabilitas

\begin{tabular}{|c|c|c|}
\hline $\begin{array}{c}\text { Skala } \\
\text { Numerical }\end{array}$ & Likelihood & Probabilitas Risk(dalam 1 tahun) \\
\hline 5 & $\begin{array}{l}\text { Almost } \\
\text { Certain }\end{array}$ & $\begin{array}{l}\text { Sangat sering terjadi denganfrekuensi }>15 \\
\text { kerusakan }\end{array}$ \\
\hline 4 & Likely & $\begin{array}{l}\text { Sering Terjadi dengan frekuensi 11-15 kali } \\
\text { Kerusakan }\end{array}$ \\
\hline 3 & Possible & $\begin{array}{l}\text { Kadang-kadang terjadi dengan frekuensi 6-10 kali } \\
\text { kerusakan }\end{array}$ \\
\hline 2 & Unlikely & Jarang terjadi dengan Frekuensi 2-5 kali kerusakan \\
\hline 1 & $\begin{array}{l}\text { Rare/Almost } \\
\text { Never }\end{array}$ & $\begin{array}{l}\text { Sangat jarang terjadi dengan frekuensi }<2 \text { kali } \\
\text { kerusakan }\end{array}$ \\
\hline
\end{tabular}

Tabel 3 Skala dampak adalah indikator dalam mengukur seberapa besar resiko kerusakan mesin yang diidentikasi pada proses produksi. 
Jurnal Teknologi dan Manajemen Industri, Vol. 5 No. 2, Agustus 2019

Pascasarjana Institut Teknologi Nasional Malang

Tabel 3. Skala Dampak Resiko

\begin{tabular}{|c|l|l|}
\hline $\begin{array}{c}\text { Skala } \\
\text { Numerical }\end{array}$ & Dampak & \multicolumn{1}{c|}{ Organizational Impact } \\
\hline 1 & Insignificant & $\begin{array}{l}\text { Kerusakan Mesin Tidak Mempengaruhi } \\
\text { Schedule Produksi dan Output }\end{array}$ \\
\hline 2 & Minor & $\begin{array}{l}\text { Kerusakan Mesin Menghambat Schedule Produksi } \\
\text { Tetapi Masih Dapat Beroperasi }\end{array}$ \\
\hline 3 & Moderate & $\begin{array}{l}\text { Kerusakan Mesin mengganggu Schedule produksi } \\
\text { dan Butuh Penanganan }\end{array}$ \\
\hline 4 & Major & $\begin{array}{l}\text { Kerusakan Mesin Sangat Mengganggu Schedule produksi } \\
\text { dan Butuh Penanganan secepatnya }\end{array}$ \\
\hline 5 & Catastrophic & Schedule produksi dan output Tidak Berjalan \\
\hline
\end{tabular}

Dari hasil analisis tersebut kemudian dilakukan tahapan selanjutnya yaitu mengevaluasi resiko yang ada dengan menentukan risk rating setiap resiko yang berdasarkan pada probabilitas dan dampak. Gambar 2akan memperlihatkan bagaimana menentukan matriks resiko tersebut.

\begin{tabular}{|c|c|c|c|c|c|c|c|}
\hline \multirow{5}{*}{ 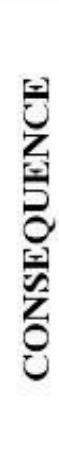 } & Catastrophic & 5 & High $(\mathrm{H})$ & High $(\mathrm{H})$ & $\operatorname{High}(\mathrm{H})$ & $\begin{array}{l}\text { Very High } \\
\text { (VH) }\end{array}$ & $\begin{array}{l}\text { Very High } \\
\text { (VH) }\end{array}$ \\
\hline & Major & 4 & $\begin{array}{l}\text { Moderate } \\
(\mathrm{M})\end{array}$ & $\begin{array}{c}\text { Moderate } \\
(\mathrm{M})\end{array}$ & $\operatorname{High}(\mathrm{H})$ & High $(\mathrm{H})$ & $\begin{array}{l}\text { Very High } \\
\text { (VH) }\end{array}$ \\
\hline & Moderate & 3 & $\begin{array}{l}\text { Moderate } \\
\text { (M) }\end{array}$ & $\begin{array}{l}\text { Moderate } \\
(\mathrm{M})\end{array}$ & $\operatorname{High}(\mathrm{H})$ & High (H) & High $(\mathrm{H})$ \\
\hline & Minor & 2 & Low (L) & Low (L) & $\begin{array}{l}\text { Moderate } \\
\text { (M) }\end{array}$ & $\begin{array}{l}\text { Moderate } \\
\text { (M) }\end{array}$ & High $(\mathrm{H})$ \\
\hline & Insignificant & 1 & Low (L) & Low (L) & Low (L) & $\begin{array}{l}\text { Moderate } \\
\text { (M) }\end{array}$ & $\begin{array}{l}\text { Moderate } \\
\text { (M) }\end{array}$ \\
\hline & & & 1 & 2 & 3 & 4 & 5 \\
\hline & & & Rare & Unlikely & Possible & Likely & $\begin{array}{l}\text { Almost } \\
\text { Certain }\end{array}$ \\
\hline & & & & & & & \\
\hline
\end{tabular}

Gambar 2. Matriks Resiko

Dari analisis resiko diatas didapat hasil evaluasi resiko yang ditunjukkan pada rating risk [3] sebagai berikut:

a. Very High atau High (tinggi) berarti resiko kerusakan mesin tersebut perlu penanganan segera/secepatnya.

b. Moderate (sedang) berarti penanganan resiko kerusakan mmesin tidak harus segera seperti resiko very high/high tetapi perlu dilakukan pemantauan khusus dalam hal penanganannya.

c. Low (rendah) berarti resiko kerusakan cukup dengan perawatan berkala dan tidak memerlukan perawatan yang spesifik.

Dari hasil penentuan risk ratingakan dibagi menurut penanganannya. Resiko kerusakan mesin atau peralatan yang berdampak sangat tinggi (very high) dan tinggi (high) pada schedule produksi harus dilakukan penanganan secepat mungkin, sedangkan resiko kerusakan mesin atau peralatan yang berdampak rendah (low) hingga sedang (moderate) merupakan batas toleransi resiko yang harus diterima [4]. Dalam menentukan akar masalah resiko kerusakan mesin tersebut perlu dilakukan penanganan yang efektif dan mengantisipasinya. 


\section{Hasil Risk Assessment}

Hasil risk assessment merupakan kajian dari beberapa tahapan mulai dari indentifikasi resiko, analisis, evaluasi hingga penanganannya kemudian dirangkum dalam suatu dokumen yang disebut sebagai risk register. Risk register merupakan kesimpulan dari hasil penilaian mengenai resiko yang meliputi dampak, probabilitas hingga tindakan yang akan dijalankan dalam menghadapi resiko [5]. Berikuthasil dari risk register pada tabel 4 sistem perawatan mesin atau peralatan di PT Bromo Steel Indonesia:

Tabel 4.Risk Register

\begin{tabular}{|c|c|c|c|c|c|c|}
\hline Risk Code & $\begin{array}{l}\text { Kerusakan } \\
\text { Component }\end{array}$ & $\begin{array}{c}\text { Likeli- } \\
\text { hood }\end{array}$ & Severity & $\begin{array}{c}\text { Rating } \\
\text { Risk }\end{array}$ & Dampak & $\begin{array}{c}\text { Risk } \\
\text { Mitigation }\end{array}$ \\
\hline R-PdM 01 & $\begin{array}{l}\text { Brake } \\
\text { System } \\
\text { Tipis }\end{array}$ & $\begin{array}{c}2 \\
\text { (Unlikeli) }\end{array}$ & $\begin{array}{c}2 \\
\text { (Minor) }\end{array}$ & $\begin{array}{l}\text { Low } \\
\text { (L) }\end{array}$ & $\begin{array}{l}\text { Kecepatan } \\
\text { mesin harus } \\
\text { perlahan-lahan } \\
\text { sehingga } \\
\text { kecepatan } \\
\text { produksi } \\
\text { berkurang }\end{array}$ & $\begin{array}{lr}\text { Perlu dilakukan } \\
\text { inspeksi } \\
\text { teknologi atau } \\
\text { memungkin } \\
\text { menampilkan } \\
\text { indicator ketebalan } \\
\text { kampas rem agar } \\
\text { bisa ditangani lebih } \\
\text { dini. }\end{array}$ \\
\hline R-PdM 02 & $\begin{array}{l}\text { Carbon } \\
\text { Brush } \\
\text { Terbakar }\end{array}$ & $\begin{array}{c}4 \\
\text { (Likely) }\end{array}$ & 2 (Minor) & $\begin{array}{c}\text { Moderat } \\
\text { e (M) }\end{array}$ & $\begin{array}{l}\text { Capaian dan } \\
\text { jadwal } \\
\text { produksi } \\
\text { terganggu }\end{array}$ & $\begin{array}{l}\text { Perlu dilakukan } \\
\text { pemeriksaan } \\
\text { predictive dengan } \\
\text { cara penggunaan } \\
\text { teknologi infrared } \\
\text { termography. }\end{array}$ \\
\hline R-PdM 03 & $\begin{array}{l}\text { Electric } \\
\text { Hoist } \\
\text { Terbakar }\end{array}$ & $\begin{array}{c}3 \\
\text { (Possible) }\end{array}$ & $\begin{array}{c}5 \\
\text { (Catastro } \\
\text { phic) }\end{array}$ & $\begin{array}{l}\text { High } \\
(\mathrm{H})\end{array}$ & $\begin{array}{l}\text { Produktifitas } \\
\text { Menurun, } \\
\text { Maintenance } \\
\text { Cost } \\
\text { Meningkat, } \\
\text { Idle time } \\
\text { produksi } \\
\text { meningkat }\end{array}$ & $\begin{array}{l}\text { Perlu membuat } \\
\text { jadwal pemeliharaan } \\
\text { yang } \\
\text { dapat digunakan } \\
\text { sebagai tolak ukur } \\
\text { melakukan } \\
\text { pemeriksaan, } \\
\text { perbaikan mesin } \\
\text { secara prediksi } \\
\text { maupun } \\
\text { preventif. }\end{array}$ \\
\hline R-PdM 04 & $\begin{array}{l}\text { Kopling } \\
\text { Tipis }\end{array}$ & $\begin{array}{c}2 \\
\text { (Unlikeli) }\end{array}$ & $\begin{array}{c}4 \\
\text { (Major) }\end{array}$ & $\begin{array}{c}\text { Moderat } \\
\text { e } \\
\text { (M) }\end{array}$ & $\begin{array}{l}\text { Jadwal } \\
\text { Produksi } \\
\text { Terganggu }\end{array}$ & $\begin{array}{lr}\text { Perlu dilakukan } \\
\text { inspeksi atau } \\
\text { teknologi untuk } \\
\text { memungkin } \\
\text { menampilkan } \\
\text { indicator ketebalan } \\
\text { kopling agar bisa } \\
\text { ditangani lebih dini. }\end{array}$ \\
\hline
\end{tabular}


Jurnal Teknologi dan Manajemen Industri, Vol. 5 No. 2, Agustus 2019

Pascasarjana Institut Teknologi Nasional Malang

\begin{tabular}{|c|c|c|c|c|c|c|}
\hline Risk Code & $\begin{array}{l}\text { Kerusakan } \\
\text { Component }\end{array}$ & $\begin{array}{l}\text { Likeli- } \\
\text { hood }\end{array}$ & Severity & $\begin{array}{c}\text { Rating } \\
\text { Risk }\end{array}$ & Dampak & $\begin{array}{c}\text { Risk } \\
\text { Mitigation }\end{array}$ \\
\hline R-PdM 05 & $\begin{array}{l}\text { Limit } \\
\text { Device } \\
\text { putus }\end{array}$ & $\begin{array}{c}2 \\
(\text { Unlikeli)) }\end{array}$ & $\begin{array}{c}1 \\
\text { (Rare) }\end{array}$ & $\begin{array}{l}\text { Low } \\
\text { (L) }\end{array}$ & $\begin{array}{l}\text { Setup mesin } \\
\text { tidak berjalan } \\
\text { dengan benar }\end{array}$ & $\begin{array}{l}\text { Perlu dilakukan } \\
\text { pemeriksaan secara } \\
\text { berkala dengan cara } \\
\text { penggunaan } \\
\text { teknologi infrared } \\
\text { termography. }\end{array}$ \\
\hline R-PdM 06 & $\begin{array}{l}\text { Spull Motor } \\
\text { Crane } \\
\text { Terbakar }\end{array}$ & $\begin{array}{c}3 \\
\text { (Possible) }\end{array}$ & $\begin{array}{c}3 \\
\text { (Moderat } \\
\text { e) }\end{array}$ & $\begin{array}{l}\text { High } \\
(\mathrm{H})\end{array}$ & $\begin{array}{l}\text { Mesin tidak } \\
\text { bergerak, idle } \\
\text { time } \\
\text { meningkat }\end{array}$ & $\begin{array}{lr}\text { Perlu dilakukan } \\
\text { inspeksi vibration } \\
\text { agar kendala bisa } \\
\text { ditangani lebih } \\
\text { cepat }\end{array}$ \\
\hline R-PdM 07 & $\begin{array}{l}\text { Roll Drum } \\
\text { Crane Aus }\end{array}$ & $\begin{array}{c}3 \\
\text { (Possible) }\end{array}$ & $\begin{array}{c}4 \\
\text { (Major) }\end{array}$ & $\begin{array}{l}\text { High } \\
(\mathrm{H})\end{array}$ & $\begin{array}{l}\text { Flow Process } \\
\text { baik Distibuis } \\
\text { Material dan } \\
\text { delivery } \\
\text { terhambat }\end{array}$ & $\begin{array}{ll}\text { Perlu } & \text { dilakukan } \\
\text { analisis } & \text { sederhana } \\
\text { kerusakan } & \\
\text { komponen } & \end{array}$ \\
\hline R-PdM 08 & $\begin{array}{l}\text { Wire Rope } \\
\text { Karat, } \\
\text { macet, }\end{array}$ & $\begin{array}{c}3 \\
\text { (Possible) }\end{array}$ & $\begin{array}{c}3 \\
\text { (Moderat } \\
\text { e) }\end{array}$ & $\begin{array}{l}\text { High } \\
(\mathrm{H})\end{array}$ & $\begin{array}{l}\text { Flow Process } \\
\text { baik Distibuis } \\
\text { Material dan } \\
\text { delivery } \\
\text { terhambat }\end{array}$ & $\begin{array}{ll}\text { Perlu dilakukan } \\
\text { analisis } & \text { sederhana } \\
\text { kerusakan } & \\
\text { komponen } & \end{array}$ \\
\hline
\end{tabular}

\section{Kesimpulan}

Berdasarkan hasil pengolahan dan analisis data diperoleh kesimpulan sebagai berikut:

Memperbaiki sistem perawatan di PT Bromo Steel Indonesia dengan melihat skala prioritas kerusakan mesin sehingga pihak perusahaan dapat menentukan kebijakan dalam meminimalisir kerugian dari resiko yang akan terjadi.

\section{Daftar Pustaka}

[1] Ahmad, Iwan Soenandi, Dan Christine Aprilia. 2013. Peningkatan Kinerja Mesin Dengan Pengukuran Nilai OEE Pada Departemen Forging Di PT AAP. Jurnal Ilmiah Teknik Industri. Vol. 1, No. 2, 67-64.

[2] Asyifa, Cut Rima. 2015. Perancangan Standart Operating Procedure (SOP) Perbaikan Dan Pemeliharaan Mesin Berdasarkan ISO 9001:2015 Klausul 7.1.3 Dengan Mempertimbangkan Konsep Risk Based Thinking di CV. XYZ. Telkom University Bandung.

[3] Leo J. Susilo Dan Victor R.K., 2013. Risiko Berbasis ISO 31000 Untuk Industri Nonperbankan. Penerbit: PPM Manjemen.

[4] Deysher, B. 2015. A Risk Based Thinking Model For ISO 9001:2015. 40

[5] Adelaide, T.U. 2009. Risk management Handbook. Adelaide Group Of Eight Member. 